\title{
Процесс биокоррозии стали и влияние на него электромагнит- ного поля
}

\author{
() Дубовик И.Е. ${ }^{1}$, Шарипова М.Ю. ${ }^{1 *}$, Гафрарова В.А. ${ }^{2}$, Наумкин Е.А. ${ }^{2}$ \\ ${ }^{1}$ Федеральное государственное бюджетное образовательное учреждение высшего \\ образования «Башкирский государственный университет» \\ Россия, Уфра, 450076, ул. Заки Валиди, 32. \\ ${ }^{2}$ Федеральное государственное бюджетное образовательное учреждение высшего \\ образования «Уфримский государственный нефтяной технический университет» \\ Россия, Уфра, 450064, ул. Космонавтов, 1.
}

\section{Email:dubovikie@mail.ru}

Исследовано влияние электромагнитного поля на биокоррозию стали марки 09Г2С. Проведен лабораторный эксперимент с использованием нитчатых цианобактерий (Nostoc linckia, Oscillatoria brevis) и одноклеточных зеленых водорослей (Mychonastes homosphaera, Chlorella vulgaris, Myrmecia incisa), которые вносились в чашки Петри с почвой и компактными образцами стали. Чашки Петри подвергались действию магнитного поля в течение 504, 1008, 1512 часов. Влияние электромагнитного поля оценивали по скорости коррозии, по изменению напряжения магнитного поля и испытанию снижения прочности металла методом малого удара. Показано, что цианобактерии и зеленые водоросли не оказывали отрицательного воздействия на скорость коррозии, снижение прочности металла, при этом наблюдалось увеличение напряжения магнитного поля.

Ключевые слова: цианобактерии, зеленые водоросли, коррозия металла, электромагнитное поле

Актуальная проблема в нефтяной и газовой промышленности - продление ресурса работы технологического оборудования с сохранением его безопасной эксплуатации. Одной из наиболее распространенных причин отказов промысловых трубопроводов была и остается коррозия трубопровода. При проведении мониторинга коррозии часто используется метод внутритрубной магнитной диагностики, что приводит к намагничиванию стенки трубопровода снарядами-дефектоскопами и созданию электромагнитного поля. При этом практически отсутствуют исследования, касающиеся влияния электромагнитного поля на биокоррозию трубопровода [1].

Биокоррозия вызывается и стимулируется жизненным процессом различных микроорганизмов (водорослей, бактерий, дрожжей, грибов) [4]. Их жизнедеятельность напрямую зависит от использования металла как питательной среды, также выделяемые продукты жизнедеятельности, оказывают разрушающее влияние на металл. Микроорганизмы, находящиеся непосредственно в воде и почве могут спровоцировать серьезные коррозионные повреждения металла. Почвогрунты определенных составов, некоторые органические продукты и застойные воды оказывают благоприятное действие для формирования и развития биологической коррозии. В основном биокоррозия наслаивается на другие типы коррозии [2]. 
Цель работы - изучение влияния электромагнитного поля на биокоррозию стали марки 09Г2С. Практическая значимость работы заключается в исследовании влияния электромагнитного поля на процесс биокоррозии металла, что позволяет установить величину влияния биоорганизмов под воздействием остаточной намагниченности после внутритрубной магнитной диагностики на функциональное состояние объекта контроля и определение способов антикоррозионной защиты, что приведет к снижению аварийности по причине биокоррозии трубопроводов.

Материалы и методы. Проводили исследования по влиянию электромагнитного поля на коррозию компактных образцов из стали марки 09Г2С при различной временной экспозиции с использованием микроорганизмов различных таксономических групп, которые являются постоянными обитателями почвы [3]. Это нитчатые цианобактерии Nostoc linckia, Oscillatoria brevis (отдел Cyanoprocaryota) и одноклеточные зеленые водоросли Mychonastes homosphaera, Chlorella vulgaris, Myrmecia incisa (отдел Chlorophya). В опытах использовали чистые культуры последних, выращенные в колбах Эрленмейера с использованием жидкой среды Громова № 6 [5].

Для проведения исследования из стержня данной марки стали были изготовлены компактные образцы токарно-фрезерным путем, конфигурация образцов имеет цилиндрическую фрорму диаметром 8 мм, толщиной 0,6 - 1,2 мм. Затем образцы обрабатывали на шлифовальном станке Metkon Grinder-Polisher 2V с использованием специально изготовленной оснастки для компактных образцов до образования толщины 0,7 мм .

Компактные образцы из стали марки 09Г2С помещали в почву с цианобактериями и зелеными водорослями в чашки Петри, и затем выдерживали их под влиянием или без магнитных полей в течение различных промежутков времени (21, 42 и 63 дня). Для создания магнитных полей устанавливали кольцевидные магниты под чашками Петри. Использовали неодимовые магниты N38 имеющие форму кольца (диаметр 50 мм, толщина 5 мм, вес 46 г, сила сцепления 13,59 кг).

Оценка коррозионной агрессивности среды. Проводили оценку коррозионной агрессивности среды по отношению к металлу образцов с использованием следующих показателей:

- среднюю скорость проникновения коррозии (П, мм/год);

- максимальную скорость проникновения местной коррозии.

Показатели коррозии (в единицах измерения - миллиметров в год) определяются по формулам ниже :

$$
\begin{aligned}
& \Pi=8760 \cdot \frac{\left(m_{0}-m_{1}\right)}{s \cdot t \cdot d} \\
& \Pi=8760 \cdot \frac{h}{t},
\end{aligned}
$$

где $\quad \mathrm{m}_{0}, \mathrm{~m}_{1}$ - массы образца до и после испытания, г;

8760 - количество часов в году;

$\mathrm{s}$ - площадь поверхности образца, $\mathrm{m}^{2}$;

$\mathrm{t}$ - время экспозиции, ч;

d - плотность металла, кг/м³;

$\mathrm{h}$ - максимальная глубина коррозионных повреждений, мм.

Коррозионную агрессивность среды оценивают по максимальному значению показателей коррозии.

Рекомендуемая продолжительность экспозиции образцов - 1 месяц. 
Определение изменения напряжения постоянного магнитного поля. Постоянное магнитное поле компактных образцов измеряли, используя измеритель концентрации напряжений ИКН-9M-12.

Метод испытания снижения предела прочности металла с малым ударом. Метод испытания снижения предела прочности при сжатии образцов проводили по показаниям Small Punch test, проведенного на сервогидравлической испытательной машине «Сервогидравлическая испытательная машина Instron 8801» со специально изготовленной оснасткой-пунсоном из стали марки У7 для компактных образцов и дальнейшей его закалкой в муфельной электропечи

Результаты и их обсуждение. Анализ данных скорости биокоррозии показал, что при длительной выдержке образцов при участии цианобактерий и зеленых водорослей не зафриксировано отрицательного воздействия их на данный параметр (табл.1). Наоборот, наблюдается некоторое снижение скорости коррозии, особенно при внесении в почву цианобактерий. Также не наблюдалось снижения прочности металла (рис.1).

Таблица1. Результаты расчета скорости коррозии (X10-7 мм/год) компактных образцов из стали марки 09Г2С после испытания в потенциально агрессивных средах

\begin{tabular}{|l|l|l|l|}
\hline \multirow{2}{*}{ Вариант опыта } & \multicolumn{3}{|l|}{ Длительность, час } \\
\cline { 2 - 4 } & 501 & 1008 & 1512 \\
\hline Почва & 1,8 & 2,1 & 1,9 \\
\hline Почва+магнитное поле & 1,8 & 1,6 & 1,4 \\
\hline Цианобактерии+магнитное поле & 2,3 & 1,8 & 1,6 \\
\hline Зеленые водоросли +магнитное поле & 1,7 & 1,6 & 1,5 \\
\hline
\end{tabular}

Сравнение характеристики напряженности магнитного поля компактных образцов из стали марки 09Г2С, выдержанных в почве вместе с цианобактениями и водорослями, показало, что напряженность при этом повышалась. Полученные показатели зависимости напряжений магнитного поля от времени выдержки приведены в табл.2.

Таблица 2. Зависимость напряженности магнитного поля (A/cм) от времени выдержки компактных образцов из стали марки 09Г2С в потенциально агрессивных средах

\begin{tabular}{|l|l|l|l|}
\hline \multirow{2}{*}{ Вариант опыта } & \multicolumn{2}{l|}{ Длительность, час } \\
\cline { 2 - 4 } & 501 & 1008 & 1512 \\
\hline Почва & 0,9 & 1,0 & 1,1 \\
\hline Почва+магнитное поле & 1,5 & 2,4 & 3,4 \\
\hline Цианобактерии+магнитное поле & 1,7 & 2,7 & 4,3 \\
\hline Зеленые водоросли +магнитное поле & 1,9 & 3,5 & 5,0 \\
\hline
\end{tabular}

Проведенные нами эксперименты не позволили сделать однозначного вывода о влиянии магнитного поля на биокоррозию при внесении культур цианобактерий и водорослей, что подтверждает необходимость проведения дальнейших исследований в данной области. 


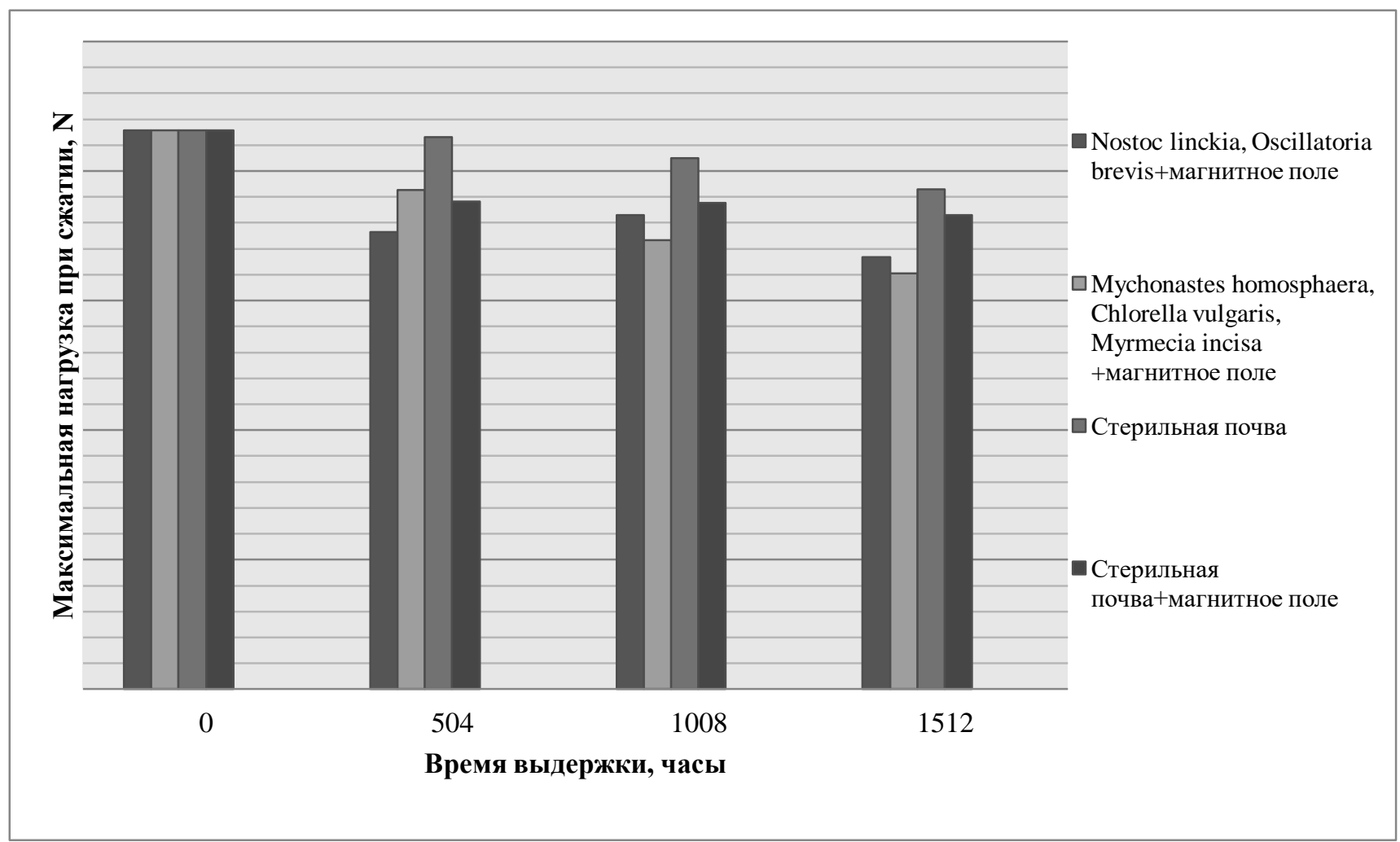

Рисунок 1. Влияние электромагнитного поля на предельную нагрузку (N) разрушения образцов.

\section{Литература.}

1. Андреева Д.Д., Фахрутдинов Р.3. Коррозионно-опасная микрофлора нефтяных месторождений // Вестник Казанского технологического университета. 2013. №10. C. 237-242.

2. Бажанова М.Е., Ерофеев В.Т. Стойкость трубопроводных материалов в условиях воздействия почвенных микроорганизмов // Вестник Белгородского государственного технологического университета им. В.Г. Шухова. 2012. № 1. С.31-33.

3. Дубовик И.Е., Наумкин Е.А., Шарипова М.Ю., Тельцова Л.3. Влияние биокоррозии на механические свойства материалов трубопроводов // Безопасность жизнедеятельности. 2019. №11 (227). С. 32-38.

4. Рязанов А.В., Вигдорович В.И., Завершинский А.Н. Биокороззия металлов. Теоретические представления, методы подавления // Вестник Тамбовского университета. Серия: Естественные и технические науки. 2003. №5. С.821-837.

5. Шарипова М. Ю., Дубовик И.Е. Современные методы альгологии. Уфа: РИЦ БашГУ, 2012. 116 с. 
The process of biocorrosion of steel and the influence of the electromagnetic field on it

Dubovik I.E. ${ }^{1 *}$, Sharipova M.Yu. ${ }^{1}$, Gafarova V.A.. ${ }^{2}$, Naumkin E.A. ${ }^{2}$

${ }^{1}$ FSBEI HE Bashkir State University, 32, Zaki Validi str., Ufa, 450076, Russia

${ }^{2}$ FSBEI HE Bashkir State Petroleum Technological University, 1 Kosmonaftov str., Ufa, , 450064, Russia

*Email:dubovikie@mail.ru

The influence of the electromagnetic field on the biocorrosion of steel grade 09G2S is investigated. A laboratory experiment was conducted using filamentous cyanobacteria (Nostoc linckia, Oscillatoria brevis) and single-celled green algae ( Mychonastes homosphaera, Chlorella vulgaris, Myrmecia incisa), which were introduced into Petri dishes with soil and compact steel samples. Petri dishes were exposed to a magnetic field for 504, 1008, 1512 hours. The influence of the electromagnetic field was evaluated by the corrosion rate, by the change in the magnetic field voltage and by testing the reduction in the strength of the metal by the small impact method. It was shown that cyanobacteria and green algae did not have a negative effect on the corrosion rate, a decrease in the strength of the metal, while an increase in the magnetic field voltage was observed.

Key words: cyanobacteria, green algae, metal corrosion, electromagnetic field 